\title{
METODOLOGIAS ATIVAS COMO ESTRATÉGIAS PARA UM APRENDIZADO SIGNIFICATIVO NO ENSINO EM SAÚDE
}

\section{ESTADO DE ARTE}

VALENTE, Antonia Regiane Pereira Duarte ${ }^{1}$

VALENTE, Antonia Regiane Pereira Duarte. Metodologias ativas como estratégias para um aprendizado significativo no ensino em saúde. Revista Científica Multidisciplinar Núcleo Do Conhecimento. Ano 06, Ed. 06, Vol. 01, pp. 05-20. Junho de 2021. ISSN: 2448-0959, Link de acesso: https://www.nucleodoconhecimento.com.br/educacao/aprendizado-

significativo, DOI: 10.32749/nucleodoconhecimento.com.br/educacao/aprendizadosignificativo

\section{RESUMO}

O presente estudo foi viável através de uma revisão integrativa da literatura a partir de publicações nacionais e internacionais dos últimos 10 anos. O mesmo abordará sobre o uso de metodologias ativas como estratégias para um aprendizado significativo no ensino em saúde. Neste contexto, os resultados evidenciam que a metodologia da problematização é a ferramenta mais empregada para subsidiar o ensino em saúde. Constata-se também que nesta modalidade de ensino o professor se mostra mais como um gestor e orientador de caminhos, os quais podem ser trilhados por parte do estudante de forma individual e coletiva possibilitando o desenvolvimento de sua autonomia como questão central no processo de aprendizagem estimulando-o a reflexão e a ação verdadeiras destes sobre a realidade. Assim, a partir do estudo considera-se que a utilização das metodologias da problematização possibilita um aprendizado significativo, uma vez que aproxima ensino e serviço, auxiliando para uma compreensão ampliada e integrada das diversas necessidades encontradas no cotidiano dos profissionais de saúde, fato este

\footnotetext{
${ }^{1}$ Mestre em Ciências da Saúde, pós graduação lato-Sensu em Enfermagem em Unidade de Terapia Intensiva e Metodologias Ativas. Graduada em Bacharel em Enfermagem.
} 
que auxiliará o acadêmico a se preparar profissionalmente para uma realidade de constantes mudanças econômicas e tecnológicas.

palavras-chave: Ensino-aprendizagem, Tecnologias, Método.

\section{INTRODUÇÃO}

O presente estudo abordará sobre as metodologias ativas no ensino superior em saúde. Tal temática mostra-se relevante uma vez que a forma com que estes profissionais serão capacitados influenciará sobremaneira na assistência em saúde à comunidade em geral.

É sabido entre os docentes que ao longo das últimas décadas os alunos mostram-se menos interessados pelos estudos, e que estes não reconhecem mais o professor como autoridade, o que compromete um eficiente e eficaz processo de ensinoaprendizagem.

O advento tecnológico, associado às mudanças sociais, contribuíram para que a organização escolar atual não atenda à necessidade real dos acadêmicos, gerando o desinteresse pelos conteúdos e pelas metodologias tradicionais até então aplicadas em sala de aula.

Nesse novo cenário que se apresenta, as instituições de ensino precisam diminuir esses abismos existentes no processo de ensino-aprendizagem. Nessa perspectiva, Marin et. al (2010), orientam a adoção de novas formas de ensino, bem como de organização curricular, de forma que este currículo seja mais flexível integrando teoria/prática, ensino/serviço, buscando sempre favorecer a motivação autônoma, despertando a "curiosidade" do aluno, à medida que este se insere na teorização, busca novos elementos, de acordo com suas perspectivas de aprendizado.

Nesse contexto, o professor passa atuar como facilitador ou orientador desse conhecimento. Para Berbel (2011, p. 29), "o aluno desenvolve o processo de aprender, utilizando experiências reais ou simuladas, visando as condições de 
solucionar com sucesso, desafios advindos das atividades essenciais da prática social, em diferentes contextos".

O processo ensino-aprendizagem faz parte do relacionamento entre os seres humanos, fato este que vem contribuído de forma ímpar para a evolução da espécie. No campo universitário, para que tal processo seja bem desenvolvido dependerá de um bom conhecimento e uso de recursos didáticos por parte do educador. Diante dessa perspectiva surge a questão problema: Como possibilitar um aprendizado significativo para os acadêmicos da área da saúde?

$\mathrm{Na}$ atualidade um dos grandes desafios das instituições de ensino em saúde é formar profissionais com competências e habilidades para utilizar a tecnologia em vigência, possuir domínio de conviver com o pluralismo social. Para tanto, se faz necessário a aplicabilidade de processos de aprendizagem com métodos interativos. Destarte, buscando responder o questionamento ao norte mencionado o presente estudo abordará sobre as metodologias ativas como estratégias para um aprendizado significativo no ensino em saúde.

Para um atendimento em saúde eficaz e com qualidade, é necessário uma análise e síntese adequadas dos dados clínicos e, baseados nesses achados o profissional tomará decisões que envolverão escolhas dentre uma ou mais alternativas que inclui riscos e benefícios.

Nesse processo de tomada de decisão o conhecimento teórico, a experiência adquirida na prática, a habilidade de julgamento e de raciocínio, são fatores que podem interferir de forma positiva ou negativa na assistência a ser prestada.

Dessa forma, o estudo em pauta se justifica, por acreditar que ouso de metodologia ativa no ensino em saúde possibilitam a articulação entre a teoria e a prática favorecendo a participação dos agentes na construção de seus conhecimentos, na troca de experiências e no questionamento sobre a sua realidade.

Assim, como forma de melhor abordar sobre estas ferramentas no uso do ensino em saúde, o estudo de forma geral objetiva apresentar os principais métodos de ensino 
aprendizagem utilizados na área da saúde. E, ainda especificamente almeja-se apontar os benefícios das metodologias ativas no aprender significativo; discorrer sobre o papel do professor como mediador na construção do conhecimento e enfatizar a autonomia do aluno como questão central no processo do aprendizado significativo;

Neste intuito buscou-se construir um estudo de revisão integrativa da literatura de caráter descritivo com abordagem qualitativa, tendo como critérios de inclusão: a) artigos publicados em periódicos científicos nacionais e internacionais revisados por pares que abordem a temática constante no banco de dados acima mencionados; que estivessem divulgados em língua portuguesa e inglesa; publicados entre o período de 2010 a 2020, ou seja, nos últimos 10 anos; que retratassem processos metodológicos ou diretrizes referentes à aplicabilidade de metodologia ativas no ensino em saúde;

A estratégia utilizada para localizar os artigos foi por intermédio das palavras-chave "Metodologias ativas" ou da combinação dos seguintes descritores: "ensino em saúde", "aprendizado", "raciocínio clínico", "estratégias de ensino", sendo que a busca de dados ocorreu entre os meses de maio a julho de 2020 sendo utilizada uma listagem dos artigos encontrados.

A apresentação e discussão dos resultados encontrados será feita de forma descritiva, possibilitando ao leitor a avaliação da aplicabilidade da revisão integrativa elaborada, de forma a atingir o objetivo desse método, ou seja, impactar positivamente na qualidade da prática do ensino em saúde, fornecendo subsídios ao docente e acadêmico para a construção de conhecimentos e trocas de experiências em suas ações cotidianas.

Para o aprofundamento desta temática no decorrer do estudo será apresentado alguns temas que favorecerão embasamento para uma melhor compreensão, dentre os quais apresenta-se: Os principais métodos de ensino-aprendizagem utilizados na área da saúde; Os benefícios das metodologias ativas para um aprender significativo e a relação professor/aluno na construção desse conhecimento. 


\section{RESULTADOS}

\subsection{OS PRINCIPAIS MÉTODOS DE ENSINO-APRENDIZAGEM UTILIZADOS NA ÁREA DA SAÚDE}

\subsubsection{METODOLOGIA DA PROBLEMATIZAÇÃO}

Nos últimos anos, baseados nas teorias de grandes ícones da educação como Piaget, Vygotsky, Ausubel, Paulo Freire e Foucaut, os educadores defendem a doutrina de uma educação libertadora, onde o aprendizado deverá ser centrado no aluno possibilitando a este a transformação do processo de conhecer, deixando para traz 0 método tradicional onde o o professor se mostrava como detentor dos saberes. Nesse contexto, a Aprendizagem Baseada em problemas (ABP) desponta como uma alternativa para a consolidação de um saber significativo.

Historicamente a Aprendizagem Baseada em Problemas desponta no século XIX, mas foi na década de 1960, na Universidade de McMaster no Canadá que essa metodologia se consolidou após um grupo de professores implementarem um instrumento novo de ensino-aprendizagem chamado de Problem Based Learning o curso de medicina - PBL. (FARIAS et. al, 2015).

No entendimento de Barrows (1986) apud Souza \& Dourados (2015), a ABP é um método de ensino que utiliza um problema como princípio para a obtenção e integração de novos conhecimentos. Nesse contexto o professor desempenha o papel de direcionador na aquisição desse conhecimento.

Conforme a interpretação de Berbell (2011) a ABP é movida pela curiosidade que leva à ação de fazer perguntas diante das dúvidas e incertezas. A autora esclarece que, tal método desafia os alunos a comprometer-se em adquirir conhecimento, através de questionamentos e investigação, em busca de respostas aos problemas identificados.

A metodologia da problematização é uma ferramenta que está sendo bastante empregada para subsidiar o ensino em saúde, dentre as quais pode-se apontar a já 
citada Problema Based Learning (PBL), o Arco de Charles e Maguerez e o estudo de Casos clínicos.

\subsubsection{PROBLEMA BASED LEARNING (PBL)}

Conforme dados da UEL (s.d), esse método mostrou-se bastante eficaz o que diferenciou os profissionais que foram submetidos à metodologia, isso despertou o interesse de vários especialistas na área da educação, fato este que possibilitou a expansão do mesmo, e atualmente várias Universidades utilizam tal ferramenta como forma de ensino-aprendizagem. No Brasil, a Faculdade de Medicina de Marília foi uma das pioneiras na utilização dessa tecnologia.

A proposta desse método é colocar $O$ aluno como elemento central do aprendizado, onde este será exposto a situações motivadoras nos grupos tutoriais, em que, através dos problemas, é levado a definir objetivos de aprendizado cognitivo sobre os temas do currículo. O princípio fundamental do método se alicerça em ensinar o aluno a aprender, admitindo que ele busque o conhecimento entre os mais variados meios de difusão de informações hoje disponibilizados, e que este aluno aprenda a utilizar e a pesquisar estes meios.

$\mathrm{Na}$ aprendizagem baseada em problemas, ao educando cabe, após discussão com seus pares identificar os problemas e buscar solucioná-los através de consultorias com os tutores e demais professores, os quais atuam no direcionamento do processo de aprendizagem, objetivando que, no final o aluno adquira habilidades necessárias para realizar atividades em grupo de forma mais criativa, proativa e crítica, tornandose capaz de transformar uma realidade social.

Godinho et. al (2017), informa que para a aplicabilidade desse método o docente elabora e apresenta ao aluno um problema próximo do real, cabendo a este discutir com seus pares tal problemática, e a partir de pesquisa e de consultorias com professores tutores buscar a resolução. Como consequência, espera-se que no final do processo o discente venha a adquirir maior habilidade para o trabalho em equipe, sendo mais criativo, proativo, crítico e transformador social. Na concepção de Farias 
(2015), essa proposta possibilita que o estudante empregue os conhecimentos adquiridos de forma ampliada, minimizando a ocorrência de uma educação fragmentada.

Esse método, de acordo com a Universidade de Maastricht na Holanda, é trabalhado com pequenos grupos de cerca de 10 a 12 membros com atividades divididas tipicamente em etapas, conforme demonstrado na ilustração abaixo.

Figura1: Os sete passos para aplicação do PBL(Problem based learning).

\begin{abstract}
Passo 1 - Identificar e elucidar termos desconhecidos apresentados no cenário; fazer uma lista daqueles que permanecem sem explicação após a discussão.

Passo 2 - Definir o problema ou problemas a serem discutidos. Nesta fase, os alunos podem ter diferentes pontos de vista sobre as questões, mas todos devem ser considerados. Devem-se realizar os registros da lista dos problemas acordados.

Passo 3 - Realizar uma sessão de brainstorming para discutir o(s) problema(s), sugerindo possíveis explicações com base no conhecimento prévio. Os alunos devem se basear no conhecimento um do outro e identificar as áreas de conhecimento incompleto. Mais uma vez, é necessário registrar toda a discussão.

Passo 4 - Revisar as etapas 2 e 3 e disponibilizar explicações como tentativas de solução. Registrar e organizar as explicações e reestruturá-las se necessário.

Passo 5 - Estabelecer objetivos de aprendizagem. 0 grupo chega a um consenso sobre os objetivos de aprendizagem. $O$ tutor garante que os objetivos de aprendizagem sejam focados, realizáveis, abrangentes e apropriados ao caso.

Passo 6 - Estudo individual (todos os alunos devem reunir informações relacionadas a cada objetivo de aprendizagem).

Passo 7 - 0 grupo parte dos resultados do estudo privado (os alunos apontam seus recursos de aprendizagem e compartilham seus resultados) para uma discussão coletiva. O tutor verifica o aprendizado e pode avaliar o grupo.
\end{abstract}

Fonte: Farias et. al. (2015)

Em consonância com os autores ao norte mencionados, acredita-se que o método PBL conduz o acadêmico da área da saúde a um aprendizado significativo, visto que ao buscar resolver problemas inerentes à sua futura profissão de alguma forma o torna 
promotor principal no processo de investigação, análise e síntese do problema investigado, competência essa que será muito explorada no seu cotidiano profissional.

\subsubsection{ARCO DE CHARLES E MANGUEREZ}

O Arco de Charles e Manguerez fundamenta-se em uma das teorias de Paulo Freire, cuja concepção é baseada em uma educação libertadora, dialógica, reflexiva, conscientizadora, transformadora e crítica, em que os problemas partem de uma realidade.

Apresentado inicialmente por Bordenave e Pereira (1982), o arco de Maguerez se baseia na análise de problemas da realidade onde o acadêmico é convidado a observação de uma realidade em determinado local escolhido por ele ou pelo professor/orientador, após a análise das características do local, o aluno irá definir problemas, refletir sobre as possíveis situações determinantes que tem relação com o problema. (FARIAS 2015).

Todas essas etapas são representadas na ilustração do Arco de Maguerez, que demonstra a passagem por cada fase do processo de solução do problema (figura 2) 
Figura 2. Arco de Maguerez

\section{Proposta de Maguerez Método do Arco}

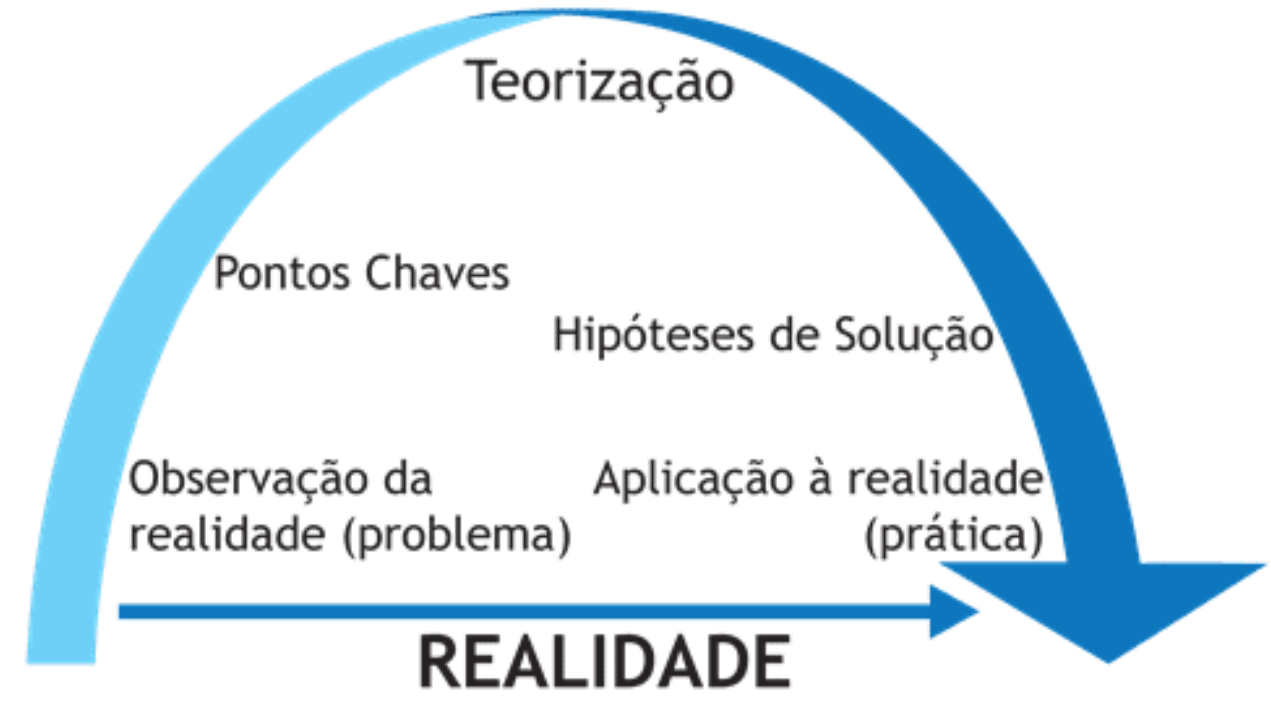

Fonte: http://tccrosangelamenta.pbworks.com/PA

Na concepção de Berbel (2011) o referido método abrange um do propósito maior que é preparar o estudante, conscientizando-o da realidade, além de atuar de forma intencional para transformá-lo, sempre para melhor, para um mundo e uma sociedade que favoreça uma vida mais digna para o próprio homem. Na ótica de Marin et. al. (2018), por partirem de situações reais, essa ferramenta estimula o estudo constante, a independência e a responsabilidade do aluno.

Percebe-se que para a aplicabilidade do método do Arco de Manguerez se faz necessário interação social, fato que oportuniza confronto, comparação e discussão sobre ideias previas de cada membro com as perspectivas dos demais, o que certamente contribui para o aprimoramento do espirito em equipe, peça fundamental para um bom desempenho no mundo do trabalho em saúde.

A exibição de tais estudos possibilita destacar que a utilização do método de ensino apresentado proporciona uma a aprendizagem significativa e duradoura, além de 
fomentar o desejo de aprender no estudante, de forma a se torne estimulado a produzir o próprio conhecimento.

\subsubsection{MÉTODO DE CASOS}

No ensino em saúde, tem-se utilizado o estudo de caso clínico como estratégia problematizadora e humanística, uma vez que viabiliza momentos de discussão acerca do conhecimento teórico e prático, além do planejamento da assistência e avaliação dos resultados. Na concepção de Schaurich et. al. (2007), essa metodologia incita a autonomia do discente na tomada de decisão em função de traçar um plano assistencial.

No entendimento de Santos et. al (2018), o método consiste na apresentação de um determinado problema ao estudante, mobilizando-o para a busca de uma solução a partir do pensamento crítico, reflexivo e criativo.

Para a aplicabilidade do método, Mayer (2012), orienta sobre 3 etapas a serem seguidas: (i) apresentação do caso ao aluno pelo professor/tutor, o qual ainda indica as principais fontes teóricas, e a partir disso prepara-se para a discussão; (ii) Realização de debate em grupos menores, onde o aluno confronta as suas reflexões e respostas com as dos demais colegas, durante esta etapa busca-se, ampliar a visão e chegar a diferentes conclusões; e (iii) discussão em sala de aula, em que cada aluno, na assembleia, é responsável pelas suas ideias e conclusões, que devem ser defendidas, conduzida pelo professor por meio de um processo de questionamento crítico preparado por ele.

Observa-se que o estudo de caso, é considerado mais do que uma tática para integrar saberes adquiridos, uma vez que proporciona ao acadêmico a oportunidade de aperfeiçoar o entendimento clínico, o que favorecerá uma melhor tomada de decisão frente a complexidade do cuidado no âmbito da saúde.

Silva et. al. (2014), entende que a utilização de estudos de casos clínicos como metodologia no ensino superior proporciona aos acadêmicos uma maior segurança 
para propor intervenções na sociedade, de modo a contribuir com a promoção da saúde, recuperação ou reabilitação de pessoas, além de contribuir para que estes estejam preparados para identificar fatores que possam influenciar no agravamento de doenças, favorecendo assim ações preventivas por parte do poder público.

O autor ainda reitera que ao formar profissionais de saúde com excelência, as instituições de ensino contribuem de forma ímpar para a prevenção e controle agravos para a sociedade, e a utilização de metodologias ativas como os estudos de casos clínicos contribuem de forma ímpar para a formação desses profissionais.

Percebe-se uma consonância entre os autores quando se referem a ABP, estes descrevem com veemência que a utilização desse método no ensino em saúde promove a aquisição de conhecimentos, o desenvolvimento de habilidades, de competências e atitudes em todo processo de aprendizagem, além de favorecer a aplicação de seus princípios em outros contextos da vida do aluno. Assim, considerase que a metodologia da problematização se apresenta como um modelo didático que promove uma aprendizagem integrada e contextualizada.

\subsection{OS BENEFÍCIOS DAS METODOLOGIAS ATIVAS PARA UM APRENDER SIGNIFICATIVO E A RELAÇÃO PROFESSOR/ALUNO NA CONSTRUÇÃO DESSE CONHECIMENTO}

Aprender é um processo cognitivo e, segundo a percepção de Padilha (2019) o que se aprende passa a subsidiar a nossa mente, de forma que quando nos deparamos com alguma informação nova, iniciamos um processo de busca mental de algo que se aproxime daquela nova informação.

Padilha (2019), salienta que o criador da Teoria da Aprendizagem Significativa David Ausubel, denominava os conhecimentos prévios de Subsunçor ou ideia âncora, pois na percepção deste estudioso, estas informações prévias apoiam e contribuem para que o novo conhecimento seja incorporado na estrutura cognitiva do aprendiz.

Nesse sentido, Moreira (2012, p. 2), reitera que 
a aprendizagem significativa se caracteriza pela interação entre conhecimentos prévios e conhecimentos novos, e que essa interação é não-literal e não-arbitrária. Nesse processo, os novos conhecimentos adquirem significado para $o$ sujeito $e$ os conhecimentos prévios adquirem novos significados ou maior estabilidade cognitiva.

Diante do exposto, é prudente ponderar que a integração do conhecimento se mostra como uma vantagem na $\mathrm{ABP}$, pois possibilita uma maior fixação e transferência dos saberes. Corroborando com o já enfatizado, Paulo Freire, escritor considerado como um dos defensores do uso de metodologias ativas no processo de ensino aprendizagem, orienta que, para estimular a aprendizagem do acadêmico são necessárias a utilização de ferramentas que os instiguem à superação de desafios, a resolução de problemas e a construção de novos conhecimentos a partir de experiências prévias.

Neste sentido, apresenta-se o Inciso I do Art. 3ำ da Resolução CNE/CES nำ3/2001, que Institui Diretrizes Curriculares Nacionais do Curso de Graduação em Enfermagem, no qual o Ministério da Educação recomenda o uso de Metodologias Ativas como estratégia para ampliar as competências e habilidades na formação do enfermeiro. Em consonância O Ministério da Saúde ressalta que cursos de graduação da área da saúde e as Políticas de Atenção Básica em Saúde, devem se desenvolver de maneira a produzir ações de promoção, a partir de problemas reais práticos que requerem transformações/soluções, e propõe a utilização de ferramentas que impulsione tais ações, e as metodologias ativas se mostram como uma opção.

Aprender por meio da problematização e/ou da resolução de problemas de sua área, possibilita a inclusão dos alunos em seu próprio processo de formação. Para Souza e Dourado (2015), o uso desse método estimula os alunos a envolverem-se mais na aprendizagem uma vez que possibilita este a interagir com a realidade e observar os resultados desse processo. Tendo como consequência o despertar da criatividade, além de estimular a liberdade e autonomia para tomada de decisões diante de situações vivenciadas. 
Na concepção de Bebel (2011), a utilização de metodologias ativas no ensino em saúde possibilita maior curiosidade à medida que o acadêmico busca por teorias as quais trazem novas informações que por vezes não são consideradas nas aulas ou no próprio ponto de vista do professor, o que propicia o fortalecimento da percepção do aluno como autor principal de seu aprendizado.

No processo de aplicação das metodologias ativas, Souza e Dourado (2015) salientam que o professor/tutor deve se responsabilizar pela criação e/ou apresentação do cenário problemático; colaborar com o processo de aprendizagem; ajudar na aquisição dos conhecimentos conceituais da disciplina; acompanhar o processo de investigação e resolução dos problemas além de potencializar o desenvolvimento das competências de análise e síntese da informação.

Nesse contexto, os autores ao norte citados ainda enfatizam que o papel do professor deixa de ser o de ensinar, e passa a ser o de ajudar o aluno a aprender, de maneira a agir como facilitador do aprendizado, valorizando conhecimentos prévios dos alunos, e suas experiências adquiridas, propondo-Ihes desafios e incentivando o seu potencial para novas aprendizagens. Possibilitando a estes uma aprendizagem autodirigida, auto orientada, e motivadora, levando-os à compreensão de que aprender não é apenas adquirir informações, mas processar as informações para transformá-las em conhecimentos.

Baseado nestas premissas, entende-se que a relação professor-acadêmico determina o processo de aprendizagem em nível universitário, pois a partir desta haverá ou não um elo de ligação e de comprometimento com a construção do conhecimento. Corroborando com esse pensamento Borges e Alencar (2014), orientam que o professor assuma uma postura de parceria e corresponsabilidade com os alunos, onde o mesmo venha a utilizar técnicas que facilitem a participação, considerando os alunos não como adjuvantes e sim como protagonistas de seu processo de aprendizado.

Percebe-se assim, que aproximar o conteúdo a ser abordado com as experiências e vivências do aluno permite um melhor aprendizado, favorecendo uma formação crítico 
social. E, nesse contexto o professor precisa compreender que ensinar não se baseia em transferir conhecimento, mas que ensinar é possibilitar ao aluno momentos de reelaboração do saber dividido, permitindo o seu acesso critico a esses saberes e contribuindo para sua atuação como ser ativo e crítico no processo histórico-cultural da sociedade.

\section{ANÁLISE DA SITUAÇÃO OBSERVADA}

Em uma realidade de informações dinâmicas, oportunidade e caminhos diversos, se faz necessário um processo de ensino que estabeleça uma relação diferenciada com o aluno, possibilitada construção do saber e promoção da aprendizagem, e nesse contexto o professor não deve se limitar na habilidade de dar a aula e/ou informando o aluno a partir de conteúdo, mas também, é premente que este lance mão de métodos de ensino que possibilitem uma aprendizagem significativa.

Para tanto, verifica-se a exigência de um rigor metodológico, dando importância aos saberes dos estudantes, reflexão, criticidade e ética, aceitação do novo e rejeição de qualquer forma de discriminação. Tais particularidades atribuídas ao ensino servem de norte para uma proposta educacional que possibilite um aprender livre, seguro, disciplinado, responsável e cooperativo.

No processo de ensino aprendizagem a partir das metodologias da problematização, evidencia-se que este precisa ser compartilhado por todos os autores envolvidos no ensinar e aprender, no qual todos devem ter a consciência do incompleto e da infinidade do processo de conhecer onde a curiosidade e a postura ativa do educador e educando são indispensáveis para o sucesso da aprendizagem.

Percebe-se que na educação problematizadora, o professor assume uma postura mais de um gestor e orientador de caminhos coletivos e individuais incentivando a construção de conhecimentos mais amplo, criativo e empreendedor. Neste cenário, a aprendizagem acontece como resultado do desafio de uma situação problema, no qual o aluno é levado a buscar por teorização sobre o tema, possibilitando ao aluno 
uma visão global e analítica do mesmo, favorecendo a este à compreensão dos fatos, tornando-o assim, protagonista do seu próprio aprendizado.

Verifica-se que o desenvolvimento da autonomia do aluno como questão central no processo de aprendizagem por meio das metodologias ativas estimula a reflexão e a ação verdadeiras destes sobre a realidade. Outro quesito importante no uso dessa metodologia, é a utilização do trabalho em equipe, uma vez que tal dinâmica requer a articulação com outros profissionais, o que é extremamente válido por propiciar o levantamento de diferentes olhares sobre um mesmo fenômeno, passando a compreender a importância da interdisciplinaridade.

Constata-se que para a efetivação de uma aprendizagem significativa é necessária a compreensão de significados, relacionando-se às experiências anteriores e vivências pessoais dos aprendizes, favorecendo aos mesmos o levantamento de problemas e busca por soluções, fato que irá instigá-los a aprender mais, além de habilitá-los a fazer correlações entre fatos, objetos, acontecimentos, noções e conceitos, modificações de comportamentos em diferentes situações. Percebe-se que na atualidade esse método de ensino se faz relevante, visto que raramente os ensinamentos recebido/aprendidos nos primeiros anos continuarão inalterados até à sua formação. Acredita-se que somente com essa postura de aprimoramento constante torna-se possível sobreviver profissionalmente em um mundo de constantes mudanças econômicas e tecnológicas.

\section{CONSIDERAÇÕES FINAIS}

Diante de tantas inovações tecnológicas e sociais, as práticas de ensino aprendizagem se apresentam mais dinâmicas e complexas, exigindo dos docentes uma visão multidimensional da realidade, exigindo que estes se reinventem diariamente e busquem por ferramentas de ensino que atendam os interesses e necessidades de todos os envolvidos no processo de ensino aprendizagem tendendo formar profissionais críticos, reflexivos e transformadores de suas realidades. 
Nesse contexto as metodologias ativas se mostram como instrumento promissor no processo de aprender, uma vez que têm o potencial de despertar a curiosidade, à medida que buscam maior esclarecimentos a partir de teorias, possibilitando maior autonomia em seu aprendizado.

Constata-se que várias são as possibilidades de metodologias ativas, no entanto, na área da saúde pode se destacar a aprendizagem baseada em problemas que possui como parte constituinte o Problema Based Learning (PBL), o Arco de Charles e Maguerez e o estudo de Casos clínicos. Nestas modalidades de ensino o professor se mostra mais como um gestor e orientador de caminhos, os quais podem ser trilhados por parte do estudante de forma individual e coletiva, com desfechos previsíveis e imprevisíveis, o que favorece em uma construção de conhecimento mais aberto, criativo e empreendedor.

Percebe-se que para a aplicabilidade da metodologia ativa os alunos carecem assumir responsabilidades pela própria aprendizagem, sendo capaz de colocar em pauta questionamentos relevantes para a situação apresentada, além de buscar soluções por meio de diferentes fontes, considerando a necessidade de trazer respostas confiáveis e atualizadas de forma a consolidar conhecimentos.

Assim, a partir do estudo considera-se que a utilização das metodologias da problematização possibilita um aprendizado significativo, uma vez que aproxima ensino/serviço, auxiliando para uma compreensão ampliada e integrada das diversas necessidades encontradas no cotidiano dos profissionais de saúde. Em contato com a realidade, os estudantes identificam situações-problema concretas, que permitem a construção de novos sentidos e implicam compromisso com o seu meio.

Ressalta-se que o presente estudo renúncia qualquer pretensão de generalização dos achados, compreende-se que a temática em pauta está em constante mudança e por essa razão entende-se a necessidade de outras pesquisas voltadas a esta questão, principalmente em relação às fortalezas e fragilidades no processo da metodologia da problematização, o que possibilitará trilhar caminhos mais seguros para sua aplicabilidade 


\section{REFERÊNCIAS}

BERBEL, Neusi Aparecida Navas. As metodologias ativas e a promoção da autonomia de estudantes. Semana: Ciências Sociais e Humanas, Londrina, v.32, n.1, p. 25-40, jan./jun. 2011. DOI: 10.5433/1679-0359.2011v32n1 p25. Disponível em: http://www.uel.br/revistas/uel/index.php/seminasoc/article/view/10326/0. Acesso em 20 de junho de 2020.

BORGES, Tiago Silva; ALENCAR, Gidélia. Metodologias ativas na promoção da formação crítica do Estudante: 0 uso das metodologias ativas como recurso didático na formação crítica do estudante do ensino superior. Cairu em Revista. , v.03, n.04, p.119-143, Jul/Ago 2014. , ISSN 22377719. Disponível em: https://www.cairu.br/revista/arquivos/artigos/2014_2/08\%20METODOLOGIAS\%20AT IVAS\%20NA\%20PROMOCAO\%20DA\%20FORMACAO\%20CRITICA\%20DO\%20ES TUDANTE.pdf. Acesso em 12 de maio de 2020.

BRASIL, Ministério da Educação. Resolução CNE/CES no 3, de 7 de novembro de 2001. Institui Diretrizes Curriculares Nacionais do Curso de Graduação em Enfermagem. Brasília (DF): Diário Oficial da União; 2001.

FARIAS, Pablo Antonio Maia de; MARTIN, Ana Luiza de Aguiar Rocha; CRISTO, Cinthia Sampaio. Aprendizagem ativa na educação em saúde: Percursos históricos e aplicações. Rev. Brasileira de educação médica. v.39. n.1, p. 143-158; 2015. http://dx.doi.org/10.1590/1981-52712015v39n1e00602014 . Disponível em: https://www.scielo.br/scielo.php?script=sci_arttext\&pid=S0100-55022015000100143. Acesso em 12 de maio de 2020.

FREIRE, Paulo. Pedagogia da Autonomia - saberes necessários à prática educativa. São Paulo: Paz e Terra, 1996.

GODINHO, Polyana Antunes; OLENIKI, Nicolle Portela; BARONEZA, Andréa Maria. et. al. A aprendizagem baseada em problemas (ABP) como metodologia de ensino na disciplina de embriologia na visão do aluno. Acta Scientiarum. Human 
and Social Sciences, v.39, n.3, p. 327-332, Sept.-Dec., Maringá 2017. Doi: 10.4025/actascihumansoc.v39i3.35350. Disponível em: http://periodicos.uem.br/ojs/index.php/ActaSciHumanSocSci/article/view/35350. Acesso em 05 de maio de 2020.

MAYER, Veronica Feder. Aplicações do Método caso em Sala de Aula. Rio de Janeiro: Fundação Getúlio Vargas, 2012.

MARIN, Maria José Sanches; LIMA, Edna Flor Guimarães; PAVIOTTI, Ana Beatriz; et. al. Aspectos das fortalezas e fragilidades no uso das Metodologias Ativas de Aprendizagem. Revista Brasileira de Educação Médica, v.34, n.1, p.1320; 2010. . Disponível em: https://www.scielo.br/pdf/rbem/v34n1/a03v34n1.pdf . Acesso em 26 de abril de 2020. Acesso em 05 de maio de 2020.

MOREIRA, Marco Antonio. o que é afinal aprendizagem significativa?. Qurriculum, La Laguna, Espanha, 2012. Disponível em: http://moreira.if.ufrgs.br/oqueeafinal.pdf. Acesso em 20 de junho de 2020.

PADILHA, Maria Auxiliadora Soares. Plano de Ensino a Partir das Metodologias Ativas - Unidade 2, Recife: Grupo Ser Educacional, 2019.

SANTOS, José Luiz Guedes dos; SOUZA, Carla Simone Bittencourt Neto de ; TOURINHO Francis Solange Vieira. et al. Estratégias didáticas no processo de ensino-aprendizagem de gestão em enfermagem. Texto contexto enferm. V.27, n.2, p.198-0016, Florianópolis 2018 Epub 03-Maio-2018. http://dx.doi.org/10.1590/0104-070720180001980016. Acesso em 12 de maio de 2020.

SCHAURICH Diego; CABRAL, Fernanda Beheregaray; ALMEIDA Mirian de Abreu Metodologia da problematização no ensino em enfermagem: Uma reflexão do vivido no PROFAE/RS. Esc. Anna Nery Rev. Enferm. 2007. v.11, n2, p.318-324. ISSN 1414-8145 .Disponível em: https://www.scielo.br/pdf/ean/v11n2/v11n2a21.pdf . Acesso em 20 de junho de 2020. 
SILVA, Rudval Souza; PAIXÃO, Gilvânia Patrícia do Nascimento; LINS, Daniela Batista. et. al. Estudo de caso como uma estratégia de ensino na graduação: Percepção dos graduandos em enfermagem. Rev. Cuidarte, 2014: 5(1):606-612. Disponível em: http://www.revistacuidarte.org/index.php/cuidartearticle/view/98/182. Acesso: 27 de maio de 2020.

SOUZA, Samir Cristiano de; DOURADO, Luis. APRENDIZAGEM BASEADA EM PROBLEMAS(ABP)): Um método de aprendizagem inovador para o ensino educativo. HOLOS, [S.I], v.5, p. 182 - 200, out. 2015. ISSN 1807-1600. Disponível em: <http://www2.ifrn.edu.br/ojs/index.php/HOLOS/article/view/2880>. Acesso em: 28 mai. 2020. Doi:http://doi.org/10,15628/holos.2015.2880.

UEL- Universidade Estadual de Londrina. Metodologia da Aprendizagem Baseada $\begin{array}{llll}\text { em } & \text { Problemas. } & \text { (s.d). } & \text { Disponível }\end{array}$ http://www.uel.br/pessoal/moises/Arquivos/APRENDIZAGEMBASEADAEMPROBLE MAS.pdf . Acesso: 27 de maio de 2020.

Enviado: Dezembro, 2020.

Aprovado: Junho, 2021. 